\title{
Performance of Fe-based hardfacings on hot forging die: experimental, numerical and industrial studies
}

\author{
N. Saklakoglu ${ }^{1 *}$, S. Gencalp Irizalp ${ }^{1}$, S. Dogan ${ }^{1}$, G. Ildas ${ }^{1}$, I. E. Saklakoglu ${ }^{2}$ \\ ${ }^{1}$ Celal Bayar University, Department of Mechanical Engineering, Manisa 45140, Turkey \\ ${ }^{2}$ Ege University Department of Mechanical Engineering, Izmir 35040, Turkey
}

Received 6 February 2017, received in revised form 17 November 2017, accepted 20 January 2018

\begin{abstract}
This paper is an investigation into the use of Fe-based alloys as part of wear resistant hardfacing materials in AISI 1.2714 tool steel. Four different weld hardfacing alloys were deposited on 1.2714 steel substrates using tungsten inert gas welding (TIG) process. Wear tests were carried out using a pin-on-disc wear tester at room temperature. Microhardness and micrographs of the weld overlays were obtained. High-temperature properties were estimated by numerical analysis. The phases of the hardfacings were obtained by XRD and also estimated by numerical analysis. The results from the laboratory tests were then compared with the results obtained from field studies. The results showed that some Fe-based alloys improved dies lifetime; others created poor surfaces. A Fe-based hardfacing alloy D which included high C with Cr, W, Mo had the best wear behavior among the weld overlays.
\end{abstract}

K e y w ords: hardfacing, Fe-based alloy, JmatPro, die failure mode, hot forging performance tests

\section{Introduction}

Hot forming processes are carried out in harsh working conditions with elevated temperatures, repeated thermal loads, large mechanical loads, etc. The harsh working conditions can cause premature failures of hot working dies [1]. Statistically, $70 \%$ of forging dies are discarded and not used as a part of production due to the fact they lose dimensions, as a result of abrasive wear and plastic deformation, $25 \%$ - as a result of fatigue cracks and only $5 \%$ - for other reasons (disregarding the technology guidelines, construction defects, material defects or thermal and thermochemical treatment defects) $[2,3]$.

Tool's life is affected by several variables, and it differs from case to case. In general, the surface hardness of the die decreases when the temperature of the die is increased during repeated operation which results in thermal softening during the hot forging process. The thermal softening accelerates the wear, thermal cracking, fatigue and the plastic deformation of the die [4]. Therefore, elevated temperature properties of die materials are a very important factor. Once a significant failure occurs, production must be stopped to replace or repair the die. Therefore, it is clear that the production costs can be significantly decreased if the life of the die can be improved. It has been estimated that the cost of hot forging dies makes up about $8-15 \%$ of the product's cost while unexpected die damage results in an increase in product's costs by $30 \%$ [5]. Summerville et al. [6] reported that almost $10 \%$ of the final forged product value is assigned to die wear expenses, such as re-work and replacement. According to Turk et al. [7], almost $17 \%$ of total production costs are part of forging dies, thus a significant portion of costs is related to tool degradation. For that reason, manufacturers are interested in improving the in-service life of hot forging dies and in supporting research work in this area in order to gain useful knowledge that can be used in industrial practice.

There are many ways to extend the life of a die by utilizing newer and better wear resistant die materials, reducing the intensity of the wear by optimizing the geometry of the die, proper heat treatments, coatings, etc. Furthermore, strength and hardness of a die material cannot be increased any further due to a tough core. A second layer to the forging die is necessary, by having a forging cavity be deposited with a layer of a superior die-steel it offers a good option in improving

*Corresponding author: e-mail address: nursen.saklakoglu@cbu.edu.tr 
Table 1. The chemical composition of AISI 2714 hot-working tool steel and electrodes used for hardfacing coatings

\begin{tabular}{lccccccccc}
\hline Electrodes & $\mathrm{C}$ & $\mathrm{Si}$ & $\mathrm{Mn}$ & $\mathrm{Cr}$ & $\mathrm{Ni}$ & $\mathrm{W}$ & $\mathrm{V}$ & $\mathrm{Mo}$ & $\mathrm{Fe}$ \\
\hline Tool steel & $0.50-0.60$ & $0.10-0.40$ & $0.60-0.90$ & $0.80-1.20$ & $1.50-1.80$ & - & $0.05-0.15$ & $0.35-0.55$ & $\mathrm{Bal}$ \\
299 Super & 0.1 & 0.9 & 0.8 & 29 & 9 & - & - & - & $\mathrm{Bal}$ \\
Thermo Dur & 0.7 & 0.6 & 0.7 & 10 & - & - & 7 & - & Bal \\
Capilla 64 KBS & 0.1 & 0.5 & 1 & 2.5 & - & - & - & 2.2 & $\mathrm{Bal}$ \\
Capilla 733 & 0.25 & 0.3 & 0.7 & 7.5 & - & 4.5 & - & - & Bal \\
\hline
\end{tabular}

Table 2. The electrodes used for hardfacing coatings

\begin{tabular}{lll}
\hline Electrodes & Supplier/Producer & Standard (EN-DIN) \\
\hline 299 Super & GeKaTec & EN 1600: E 29 9 R 52 \\
Thermo Dur & GeKaTec & EN 14700: E Z Fe 8 \\
Capilla 64 KBS & Capilla & EN 14700: E Fe 3 - DIN 8555: E-3-UM-350-T \\
Capilla 733 & Capilla & EN 14700: E Fe 3 - DIN 8555: E3-UM-50-T \\
\hline
\end{tabular}

the lifetime of a die, and therefore a weld-deposited working layer is rapidly becoming popular [8]. Hardfacing is currently the most popular technology and an economical method when it comes to repairing damaged dies and molds so that they may be put into operation again [9]. The fundamental principle of the hardfacing technology is the creation of a wear resistant layer on to the base material via deposition of the desired material $[1,10]$. Three types of hardfacing alloys, namely Cobalt base, Nickel base and Iron base, are the most frequently used materials for hardfacing while having different composition and different welding process parameters. Especially, Fe-based materials that have high $\mathrm{Cr}$ content are used as part of hardfacing alloys that are widely used for hardfacing in industries such as mining, forging, cement making, thermal power plants and iron and steel industries due to their higher hardness and excellent abrasive resistance which is attributed to chromium carbides being formed. Researchers have focused on the microstructural morphologies and wear resistance of hardfaced surfaces [11-15]. A few studies cover industrial results $[1,4,8]$.

This paper includes laboratory experiments, numerical analysis and field tests on hardfacing materials. Failure analysis of the discarded die includes dimensional and visual checks and laboratory studies include surface analysis, metallographic analysis, and hardness and wear studies which were completed by Deform and JMatPro calculations (a computational thermodynamic calculation tool). These numerical analysis programs are very useful tools that help in knowing the stability ranges of the phases, the nature of the carbides, high-temperature mechanical properties, thermo-physical and physical properties and some other features that help with better understanding of what failure analysis of the described system is. Therefore, the present work correlates numerical, laboratory and field tests.

\section{Industrial and laboratory procedures}

Since the final purpose of this study was to improve the wear resistance of a hot forging die made of AISI 2714 hot-working tool steel, four test blocks of this tool steel were prepared. The chemical composition of AISI 2714 hot-working tool steel and the electrodes used for hardfacing application are given in Table 1. The test blocks were hardfaced through TIG welding that used Fe-based hardfacing electrodes based on the manufacturer's recommendations. Hardfaced layers obtained using these electrodes have high wear resistance, favorable toughness and can endure high impacts during operation. These alloys were selected due to its low cost and easy availability in the local market and suitability for the service condition. We aimed to compare the welding electrode performance on the die under real forging conditions with laboratory studies and make a recommendation for real users. These electrodes and also their suppliers and norms are given in Table 2 .

The hardness value of the hardened and tempered test block was $433 \mathrm{HV}$. Table 3 shows hardfacing parameters. During the welding process, the test blocks were held at temperatures between 300 and $450^{\circ} \mathrm{C}$. Afterwards, the stress relief treatment was applied to all specimens at $450^{\circ} \mathrm{C}$ for $6 \mathrm{~h}$. For the metallographic, hardness and wear tests, samples were cut and machined from the experimental blocks (Fig. 1). The samples were ground and polished. Wear tests were performed using a pin-on-disc method.

The parameters for each wear test involved: sliding speed of $0.3 \mathrm{~m} \mathrm{~s}^{-1}$, a normal load of $10 \mathrm{~N}$ and total 
Table 3. TIG hardfacing parameters

\begin{tabular}{ll}
\hline Parameters & Values \\
\hline Voltage (V) & 180 \\
Gaseous flow rate (bar) & 15 \\
Gas mixture & $75-95 \% \mathrm{Ar}+4-22 \% \mathrm{CO}_{2}+1-3 \% \mathrm{O}_{2}$ \\
\hline
\end{tabular}
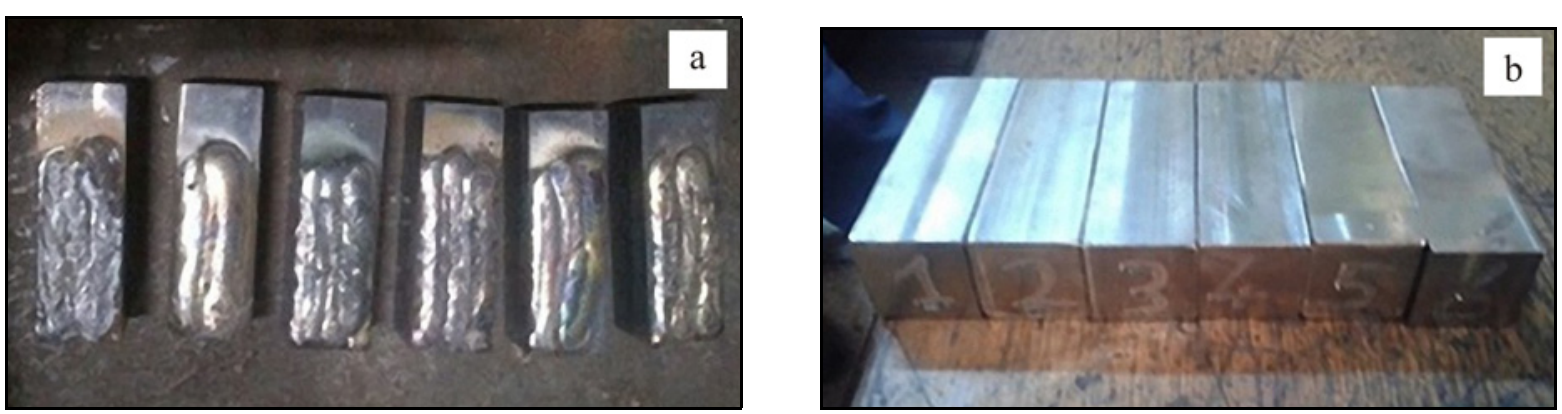

Fig. 1. The samples deposited by hardfacing alloys (a) and after hardfacing, machined and levelled out samples (b).

sliding distance of $500 \mathrm{~m}$. Regarding high hardness of hardfacing alloys, an $\mathrm{Al}_{2} \mathrm{O}_{3}$ ball (with a hardness of 1700-1800 $\mathrm{HV}_{50}$ ) was used for the counterface which is a common counterface material when tribological tests are being carried out. Before and after each experiment, the ball and disc were ultrasonically cleaned and weighed after drying. The wear rate was calculated by Eq. (1):

$$
W=\frac{\Delta V}{N L}
$$

where $W$ is the wear rate $\left(\mathrm{mm}^{3} / \mathrm{N} \mathrm{m}^{-1}\right), \Delta V$ is the wear volume $\left(\mathrm{mm}^{3}\right), N$ is the normal load during testing $(\mathrm{N})$, and $L$ is the sliding distance $(\mathrm{m})$.

All of the microhardness tests were performed using a Vickers indenter, and the hardness measurement was applied on the worn and unworn surfaces under a $300 \mathrm{gf}$ load. After the tribological test, the worn surfaces were cleaned ultrasonically, and Vickers microhardness test (HV0.3) was performed on worn surfaces under a load of $300 \mathrm{gf}$.

JmatPro software was used with thermodynamic calculations being applied to predict the type and percentage of existing phases, high-temperature properties and expansion coefficient values. JMatPro - an acronym for Java-based Materials Properties - is a powerful software package that calculates a wide range of material properties for alloys, including stable and metastable phase equilibria, solidification simulations, mechanical properties, phase transformation, thermophysical and physical properties, etc. [16].

According to the results from these laboratory experiments and calculations, one practical die was hardfaced. Before hardfacing it, the wear mechanisms and weak points were investigated using visual inspection, penetration testing and numerical simulation.
Hot forging performance tests were carried out in real working conditions in a hot forging factory in a polished state.

During the service, dimensions of the die had to be controlled at some stages, like other ordinary dies. The contour of the dies was investigated by a 3D-coordinate measuring machine in order to quantify the die wear. After a considerably long period, the die was taken out of service. The worn die was examined on a CMM to allow for the comparison of the results from the wear analysis to the worn die where 'flatness and parallelism' on the die is considered.

When the flatness and parallelism were outside the spectrum of tolerance, the hardfaced die surface was machined to allow the die to be put back into service again. The amount of machining that had to be done for every hardfaced die surface was counted.

\section{Results and discussion}

\subsection{Selection of welding electrode - laboratory studies and numerical analysis}

Hardfacing is a widely diffused technique. Owing to the considerable difference in melting points of the tool steel and the electrodes, considerable dilution from substrate occurs during hardfacing using gas tungsten arc welding process [17-19].Therefore, the chemical composition of the surfaces altered after hardfacing application.

The surface obtained by "299 Super" electrode via hardfacing process was entitled as "Alloy A"; "Thermo Dur" was entitled as "Alloy B"; "Capilla 64 KBS" was entitled as "Alloy C", and "Capilla 733" was entitled as "Alloy D". 
Table 4. The composition of sample surfaces taken by EDS analysis

\begin{tabular}{lccccccccc}
\hline & $\mathrm{Fe}$ & $\mathrm{Cr}$ & $\mathrm{Mn}$ & $\mathrm{Ni}$ & $\mathrm{C}$ & $\mathrm{Si}$ & $\mathrm{W}$ & $\mathrm{V}$ & $\mathrm{Mo}$ \\
\hline Alloy A & 74.684 & 17.904 & 0.202 & 5.216 & 0.274 & 1.722 & - & - & - \\
Alloy B & 86.737 & 8.699 & 0.012 & 1.442 & 1.778 & 1.047 & - & 0.286 & - \\
Alloy C & 89.251 & 2.762 & 0.902 & - & 1.054 & 0.758 & - & - & 5.273 \\
Alloy D & 81.556 & 4.657 & 1.132 & - & 1.156 & 1.229 & 2.526 & - & 7.744 \\
Bare Steel & 94.969 & 1.094 & 0.568 & 1.423 & 0.714 & - & - & 0.138 & 1.094 \\
\hline
\end{tabular}
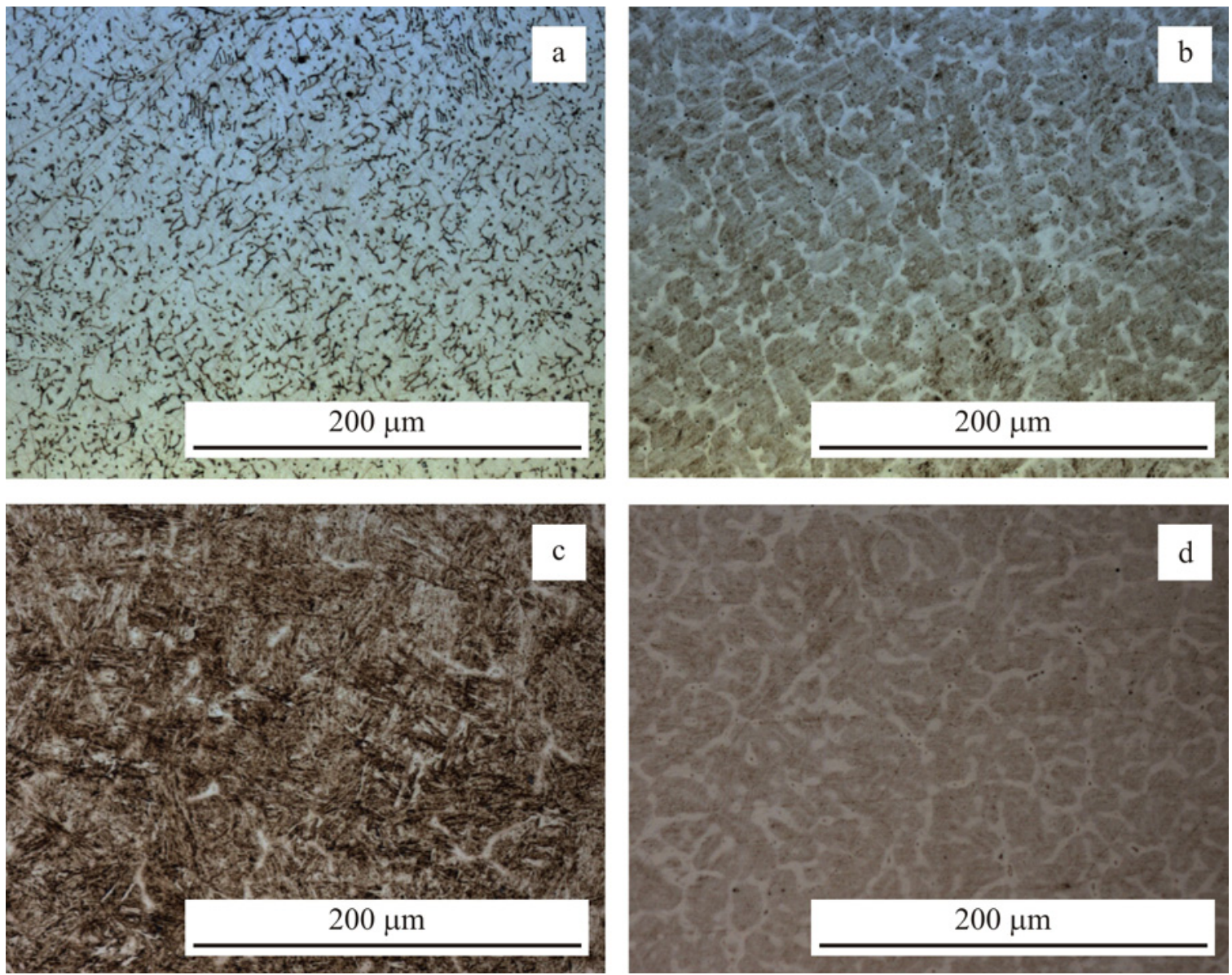

Fig. 2. Micrographs of hardfaced surface: (a) Alloy A, (b) Alloy B, (c) Alloy C, and (d) Alloy D.

The composition of hardfaced surfaces was taken via an EDS analysis, and the results are shown in Table 4. Furthermore, during numerical studies, these composition values were used. The microstructure of the hardfacing weld overlay is shown in Fig. 2. The interdendritic zone eventually solidified in the alloying element, resulting in intermetallic formations such as carbides. These carbides were formed during the weld layer solidification. Since solidification speed during welding is very high, the matrix becomes a supersaturated solid solution of alloying elements (especially $\mathrm{Cr}$ and $\mathrm{Mo}$ ) in Fe. Even though the primary carbides were not distinguishable by optical microscopy, they were confirmed to be $\mathrm{M}_{7} \mathrm{C}_{3}$ and $\mathrm{M}_{23} \mathrm{C}_{6}(\mathrm{M}=\mathrm{Cr})$ by the XRD analysis (Fig. 3).
JMatPro does not predict the size and distribution of equilibrium phases. On the other hand, JMatPro can predict the number of phases that occur depending on temperature. Figure 4 shows the phase formation after hardfacing obtained by JmatPro. XRD analysis verifies the JmatPro analysis. These calculated results are consistent with the hardness properties of the samples. As it is seen in Table 5 derived from Fig. 4, among the carbides, the $\mathrm{M}_{23} \mathrm{C}_{6}$ type had the lowest hardness. $\mathrm{M}_{6} \mathrm{C}$ and $\mathrm{M}_{7} \mathrm{C}_{3}$ were stable at higher temperatures than $\mathrm{M}_{23} \mathrm{C}_{6}$. Table 6 shows the amount of carbides that were derived from Fig. 4. As it is seen from Tables 5 and 6 , it is not surprising that Alloys $\mathrm{B}$ and $\mathrm{D}$ had higher hardness and it promises higher hardness at elevated temperatures. 

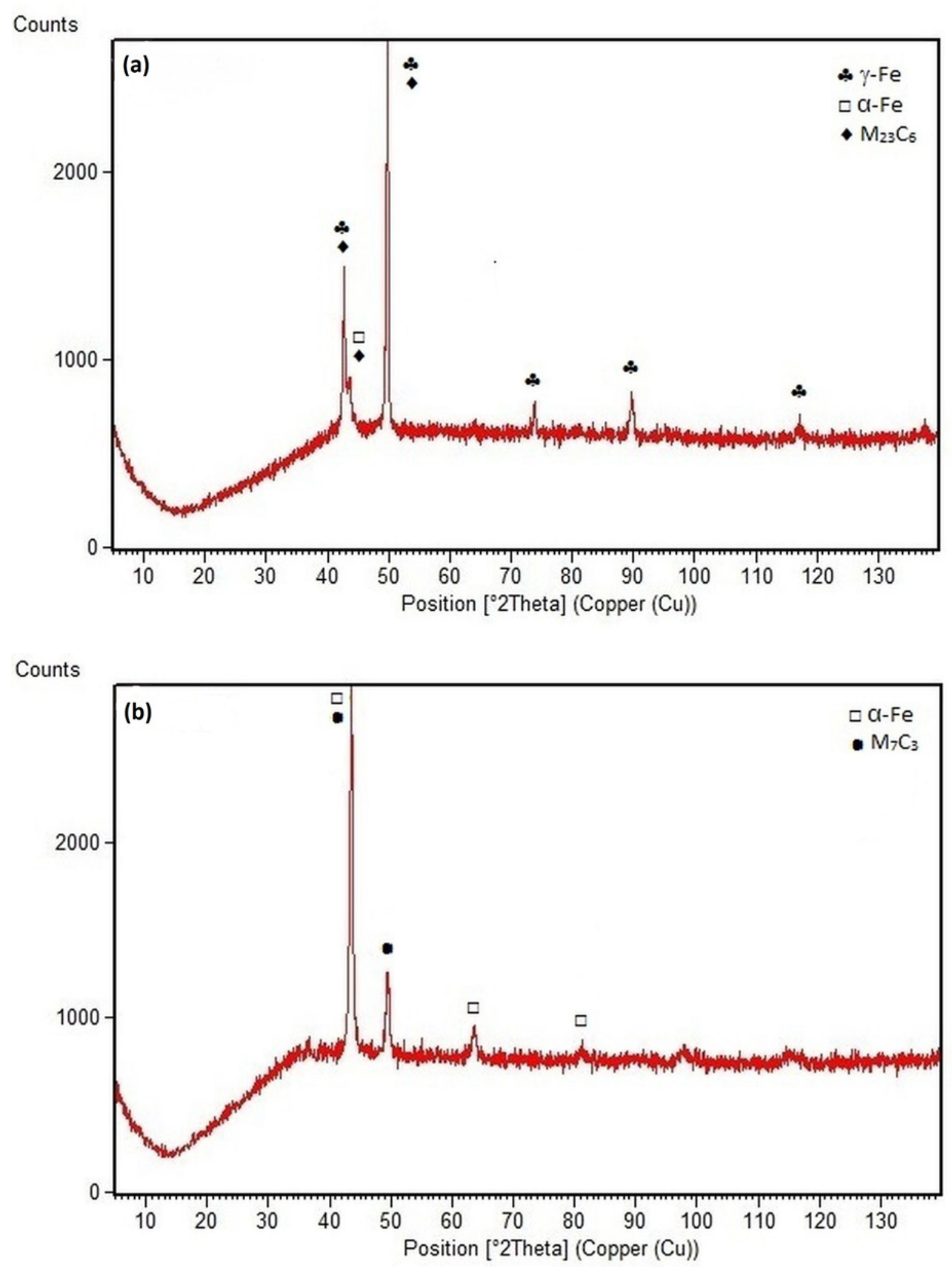

Fig. 3a,b. XRD analysis spectra of hardfacings: (a) Alloy A, (b) Alloy B.

The proof stress and thermal expansion coefficient of hardfacings were predicted by JMatPro calculations. As it is seen in Fig. 5a, Alloys B and D had higher proof stress while Alloys A and C had lower proof stress than 1.2714 tool steel. On the other hand, the expansion coefficient of Alloys B and D closely matched that of the substrate, while Alloys A and $\mathrm{C}$ had higher expansion coefficients which caused the 

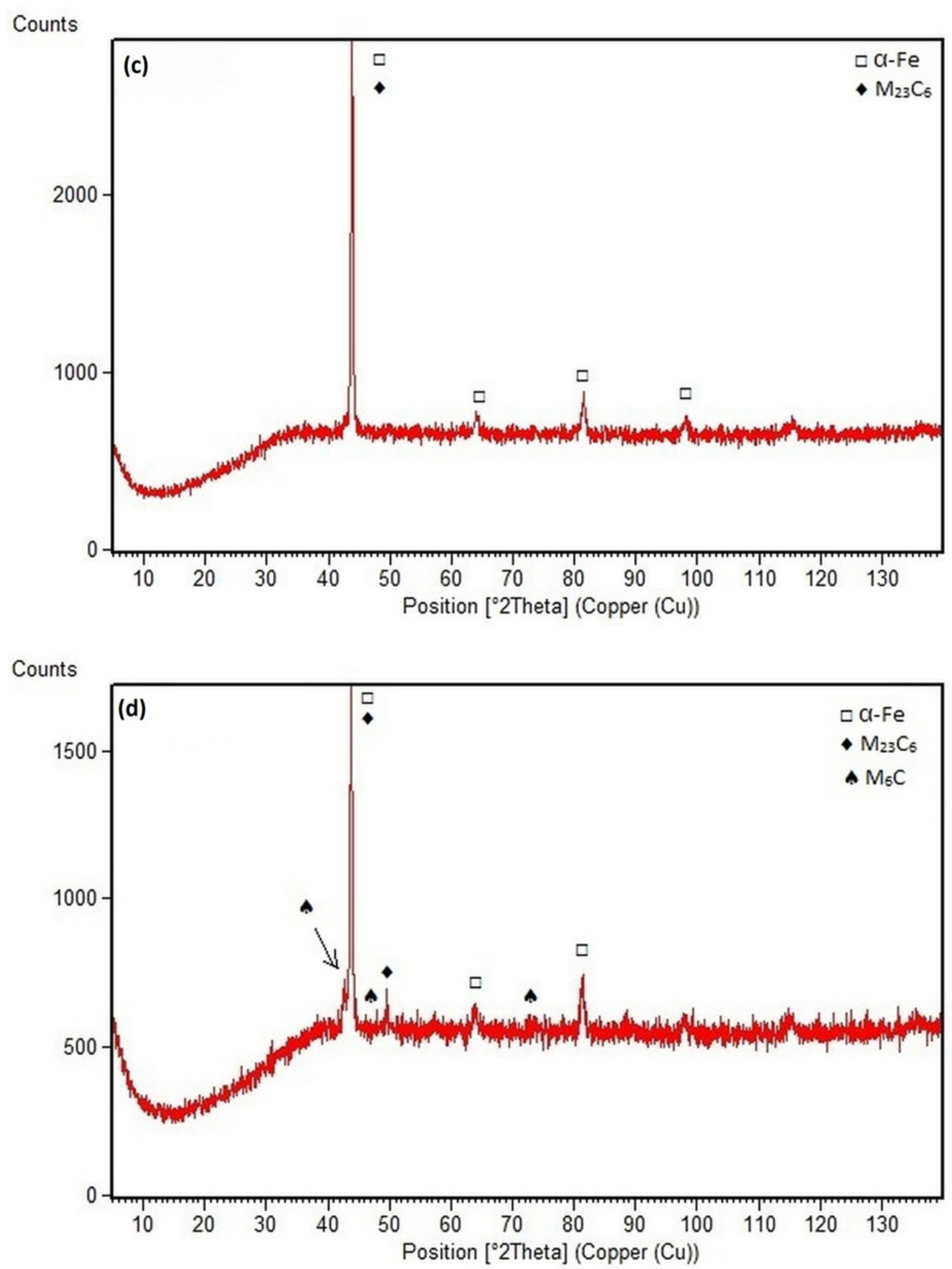

Fig. 3c,d. XRD analysis spectra of hardfacings: (c) Alloy C, (d) Alloy D.

thermal expansion mismatch stress $\left(\sigma_{\mathrm{m}}\right)$ due to the difference in the coefficients of thermal expansion that exist between the coated material and the substrate at elevated temperatures (Fig. 5b).
Hardness and wear test results are summarized in Table 7. Alloy C had highest wear rate. Although Alloy A had a lower hardness than tool steel, it had a very low wear rate. As can be seen in Table 4, it 

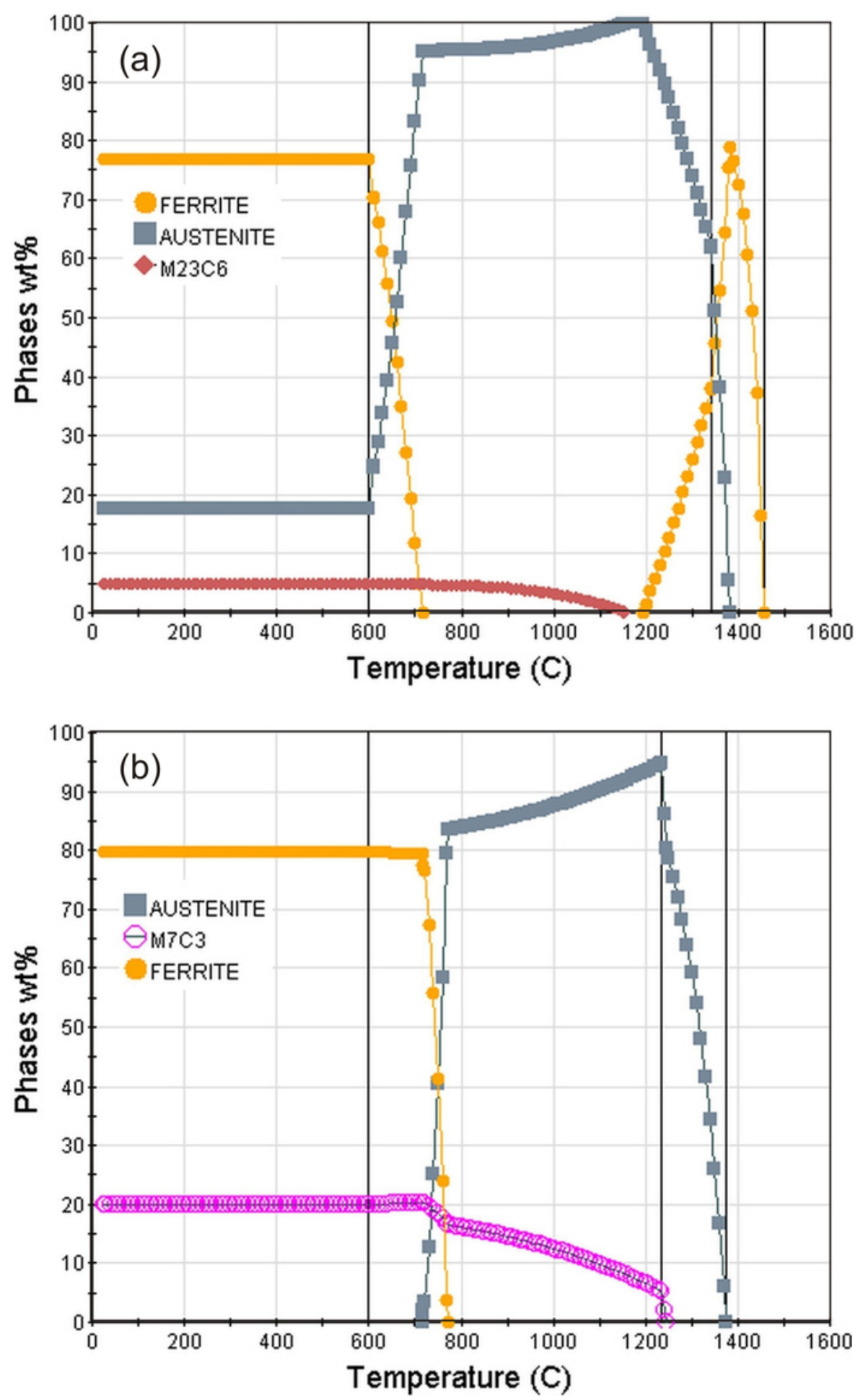

Fig. 4a,b. Phase formation after hardfacing obtained by JmatPro: (a) Alloy A, (b) Alloy B.

reached a very high hardness level after the wear test since cold work and oxide formation occurred [25-28]. It is known that when oxides are present at high temperatures they play the role of a solid lubricant by forming glazed surfaces. Therefore, an increase in a test temperature makes the oxides thicker on the disc surface [29-31]. EDS analysis (Table 8) shows that oxygen concentration increased within the wear track at the temperature shown, suggesting that oxidative wear is operative at room temperature for the samples. During this wear regime, oxidation occurs on the surface which in turn prevents contact between the rubbing surfaces and therefore reduces the wear loss. Kong Dejun et al. showed that at a high temperature 

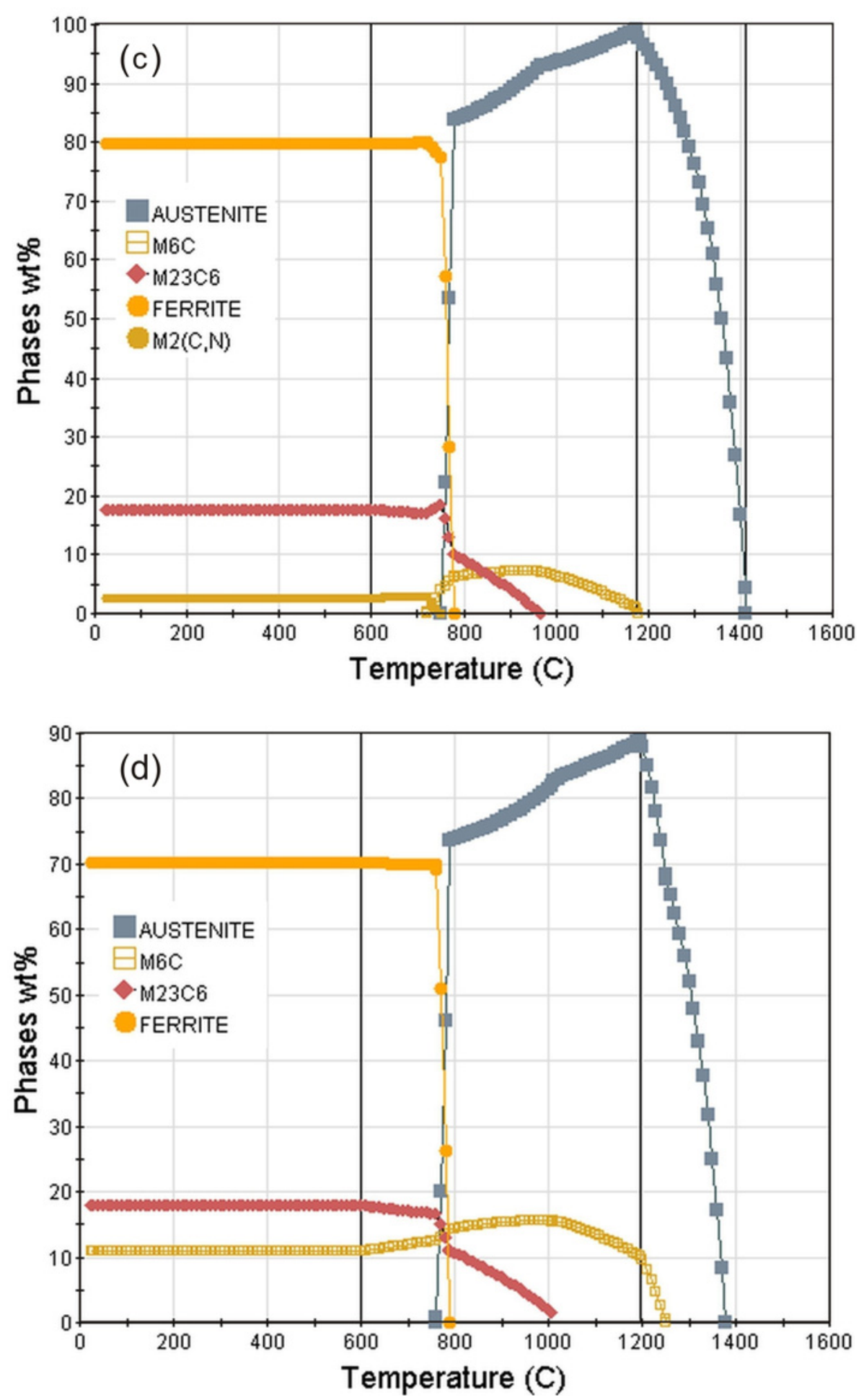

Fig. 4c,d. XRD analysis spectra of hardfacings: (c) Alloy C, (d) Alloy D.

$\left(800^{\circ} \mathrm{C}\right)$ and high load $(5,7$ and $9 \mathrm{~N})$ the friction and wear tests cause up to $12 \%$ oxygen content to occur on the wear track meaning that the wear mechanism was primarily oxidative one [31]. A. Bedolla-Jacuinde et al. [25] found that the formation of smaller sized oxide debris occurred at short sliding distances and it thickened at a longer distance. It is known that friction yields not only oxidation but also cold worked layers. This effect is called friction-induced work hardening rate $(\mathrm{FIWH})$ [25]. The formation of cold worked and a continuous oxide layer during high temperatures was identified by Jens Hardell et al. and Q. Y. Zhang et al. [27, 28]. The hardened layer acts as a lubricant if it occurs on a hard substrate. 

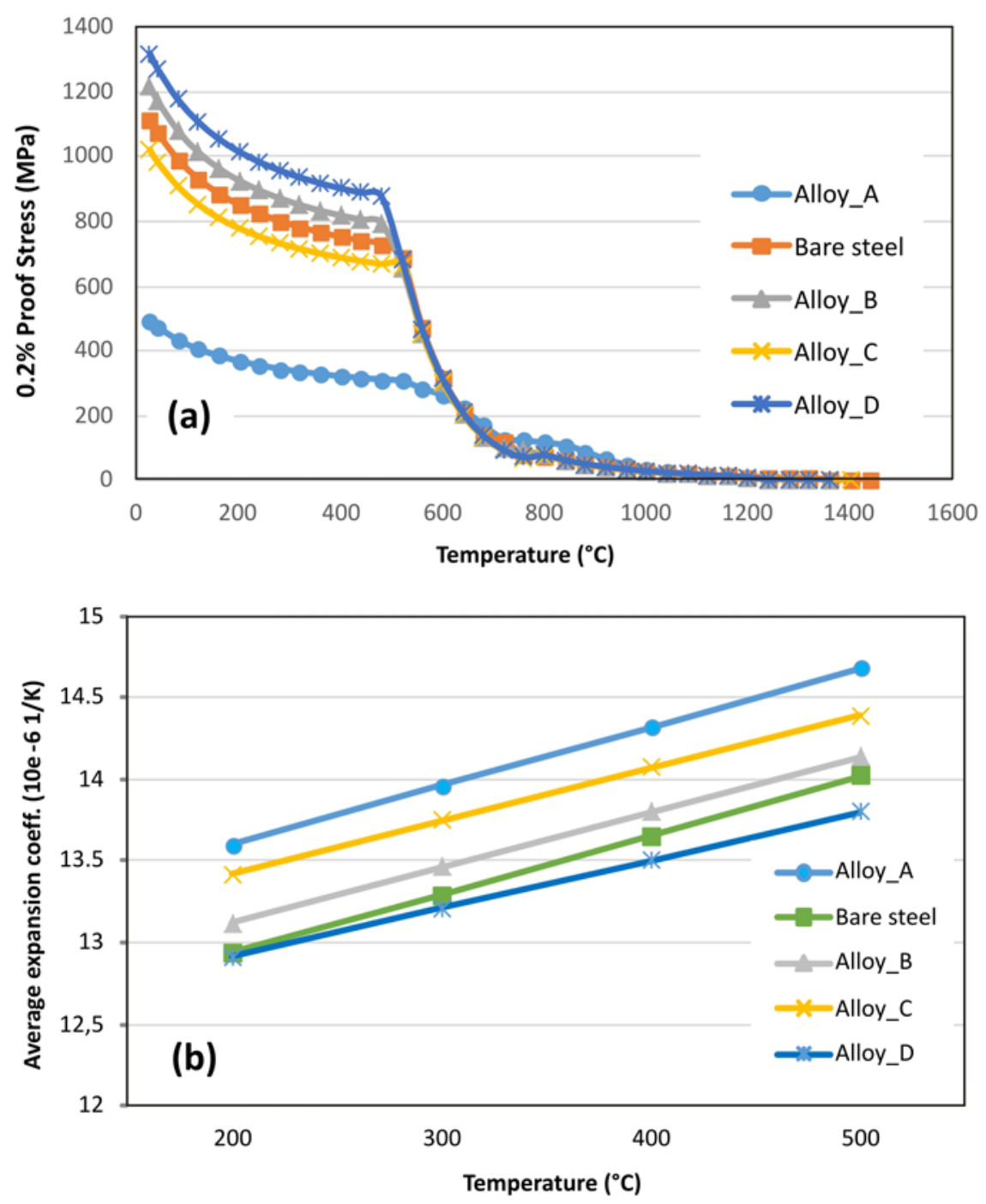

Fig. 5. The effect of temperature on the proof stress and average expansion coefficient of hardfacings obtained by JMATPRO analysis.

Ta b le 5. Hardness values of various carbides [20-24]

\begin{tabular}{ll}
\hline Carbides & Hardness, HV \\
\hline $\mathrm{M}_{7} \mathrm{C}_{3}$ & $1025-2150$ \\
$\mathrm{M}_{2} \mathrm{C}$ & $1512-2200$ \\
$\mathrm{M}_{23} \mathrm{C}_{6}$ & 800 \\
$\mathrm{M}_{6} \mathrm{C}$ & $1200-1800$ \\
Austenite & $190-350$ \\
Ferrite & $70-190$ \\
\hline
\end{tabular}

On the other hand, it is known that an oxide layer forms and grows with time because of the higher temperature that occurs during hot forging [29]. However, the wear mechanism is mainly influenced by two factors: type/thickness of the friction-induced work hardening layer and the load support that is provided by the underlying material [30]. For example, a hard layer on a soft metal surface (oxide on aluminum, for instance) may be ineffective because the soft substrate deforms, allowing the oxide to break like ice on a pond. Afterwards, the broken oxides act as abrasive particles, which increases wear [29].

In this study, the hard layer formation occurred due to the friction-induced work hardening that reduced the wear rate because of a very low load during the wear test. During the forging, there was a harsh loading, and the brittle oxide layer was harmed. Considering hardness, wear test, high-temperature strength values and the average expansion coefficient of hard facings, it was decided at the end that only the Alloys B and D would be selected for hot forging trials.

\subsection{Die failure mode}

The failure mode of the discarded non-hardfaced 
Table 6. The amount of carbides derived from Fig. 4

\begin{tabular}{lcccc}
\hline & \multicolumn{4}{c}{ The amount of carbides, $\%$} \\
\cline { 2 - 5 } & $\mathrm{M}_{23} \mathrm{C}_{6}$ & $\mathrm{M}_{7} \mathrm{C} 3$ & $\mathrm{M}_{2}(\mathrm{C}, \mathrm{N})$ & $\mathrm{M}_{6} \mathrm{C}$ \\
\hline Alloy A & 5 & - & - & - \\
Alloy B & - & 20 & - & - \\
Alloy C & 18 & - & - & 11 \\
Alloy D & 18 & - & - & \\
\hline
\end{tabular}

Table 7. The summary of experimental results

Sample Wear Rate $\left(\mathrm{mm}^{3} / \mathrm{N} \mathrm{m}^{-1}\right)$ Hardness at the surface, HV (300 gf) Hardness at the wear track, HV (300 gf)

\begin{tabular}{llll}
\hline Alloy A & 0.0577 & 226 & 749 \\
Alloy B & 0.0421 & 469 & 628 \\
Alloy C & 0.0872 & 409 & 469 \\
Alloy D & 0.0619 & 499 & 535 \\
\hline
\end{tabular}
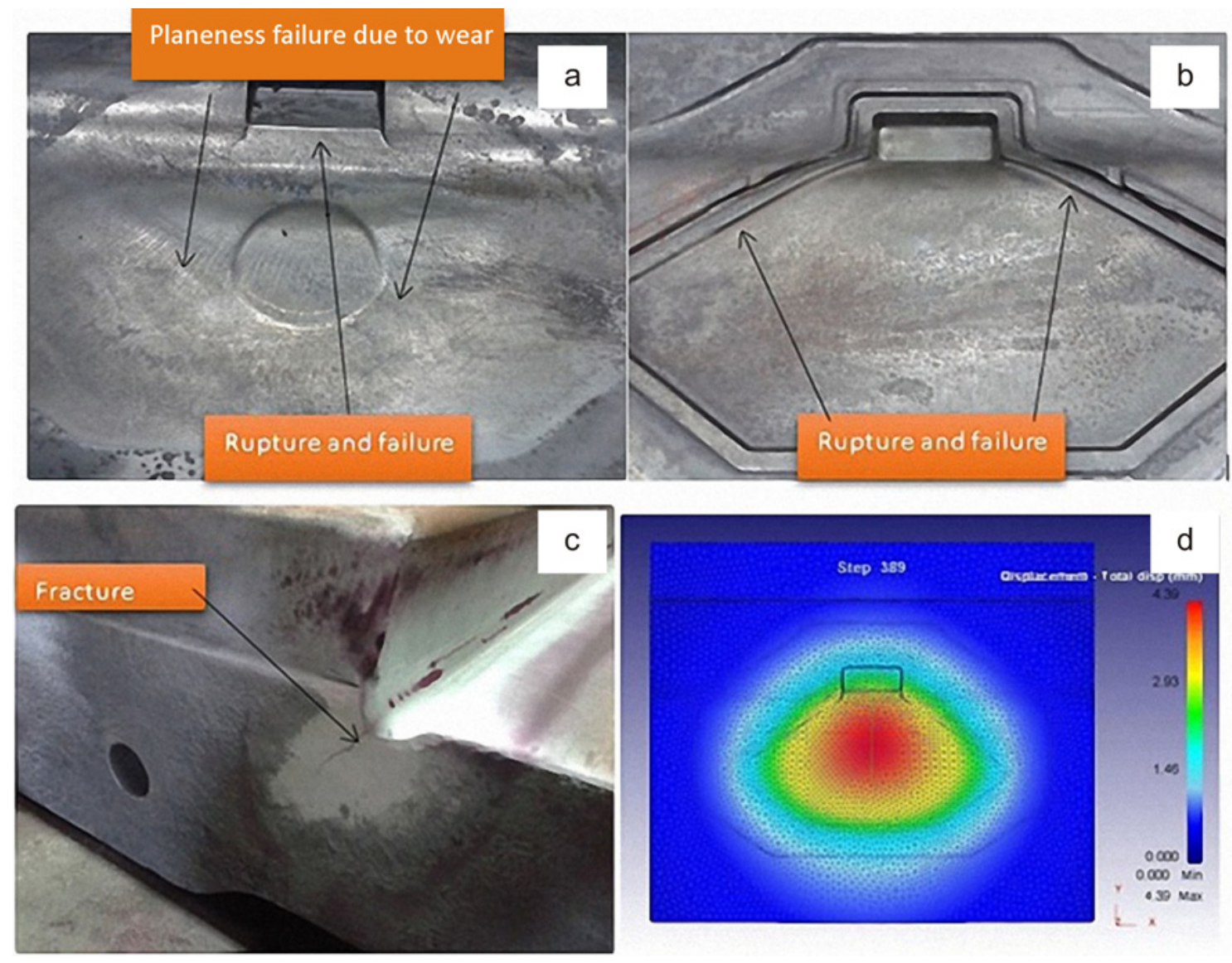

Fig. 6. Die failure mechanism after use in real production conditions in a forging plant.

dies was investigated to determine the occurrence of wear and thermal damage during forging operation and optimize suitable hardfacing regions for forging die surfaces. The general appearance of the worn die's surface provides a clear picture of the degradation.
What the main damage to the die occurred at a macro level is shown in Fig. 6. The upper die showed wear that had a plastic deformation which caused degradation to the plane flatness (see Figs. 6a,b). In addition, some cracks were determined by penetrant test 
Ta ble 8. Oxygen concentration values derived from EDS analysis

\begin{tabular}{lcc}
\hline Sample No. & Oxygen conc. at the unworn surface (wt.\%) & Oxygen conc. at the wear track (wt.\%) \\
\hline Alloy A & 0.013 & 2.165 \\
Alloy B & 0.000 & 0.766 \\
Alloy C & 0.000 & 0.240 \\
Alloy D & 0.003 & 0.522 \\
\hline
\end{tabular}

Ta ble 9. CMM results of dies after usage

\begin{tabular}{lccccccc}
\hline & \multicolumn{3}{c}{ Flatness of plane $(\mathrm{mm})$} & & \multicolumn{3}{c}{ Parallelism of plane $(\mathrm{mm})$} \\
\cline { 2 - 3 } & Measurement & Tolerance & Out of tolerance & & Measurement & Tolerance & Out of tolerance \\
\hline Bare Die & 1.4945 & 1.000 & 0.4945 & & 1.7288 & 1.000 & 0.7288 \\
Alloy B & 0.5023 & 1.000 & 0.000 & & 0.5023 & 1.000 & 0.000 \\
Alloy D & 0.3907 & 1.000 & 0.000 & & 0.4098 & 1.000 & 0.000 \\
\hline
\end{tabular}

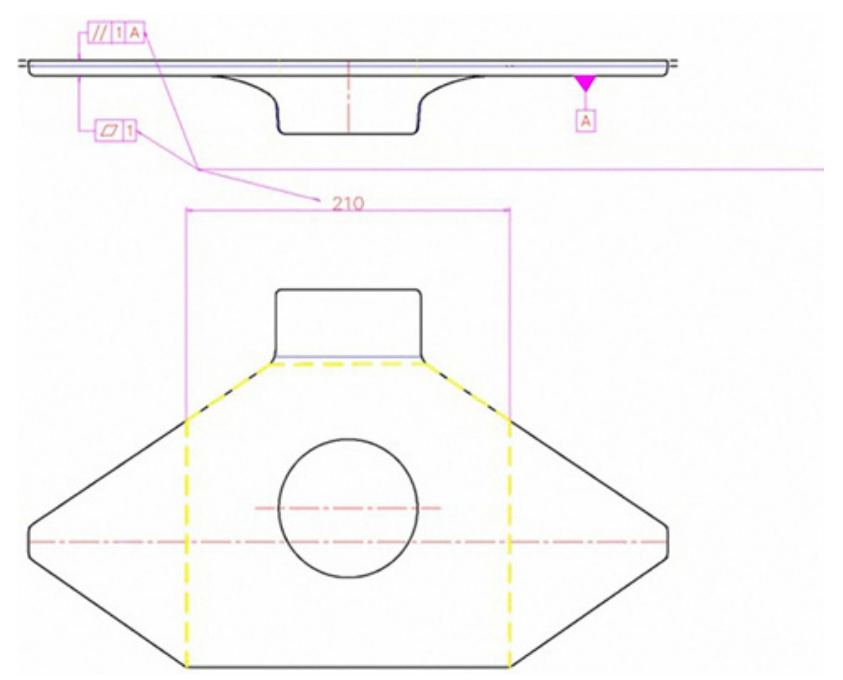

Fig. 7. Tolerance level of the flatness and parallelism of technical drawing.

(Fig. 6c). Numerical simulations indicated critical areas in the hot-forging die which corresponded to those on the real die surface (Fig. 6d) which are also critical in the service life of dies and the quality of the forged products. In these areas, stress concentration occurred due to pressure from the forged material on both surfaces and consequently due to the bending load that is accruing on the bottom of the die. These repetitive mechanical loads resulted in the formation of cracks that caused surface, geometry and shape deficiencies in the forged products [32].

\subsection{Hardfacing application on dies}

After determining the failure mechanisms and the area, the damaged areas were reworked via a CNC
Vertical Machining Center. The reworked die was heated to about $400^{\circ} \mathrm{C}$ in a resistance-type industrial furnace and then wrapped in glass wool to prevent cooling. During the hardfacing application (Table 3), it was re-heated when the die temperature had fallen below $300^{\circ} \mathrm{C}$. Only Alloys B and D were applied to the hot forging dies as indicated in section 3.1. Selection of Welding Electrode. After the hardfacing application, stress relieving treatment was applied twice at $450{ }^{\circ} \mathrm{C}$ for $6 \mathrm{~h}$.

\subsection{Hot forging performance tests}

Hot forging performance tests were carried out in real working conditions in a hot forging factory in a polished state. CMM measurements were taken before and after the forging trials to measure the extent of the failure that was produced by the forging application when the 'flatness and parallelism' on the die is considered. The flatness tolerance symbolized has two parallel planes that define a zone where the entire reference surface must lie. Parallelism symbol describes a parallel orientation of a once referenced feature of a datum surface or line. Figure 7 shows the tolerance level of the flatness and parallelism of a technical drawing that is being considered in this study.

Table 9 shows the change in flatness and parallelism of bare dies after they have been improved with Alloys B and D that were welded as overlays. For comparison, the data for bare steel were also included. The most important factor in determining the lifespan of the die is the tolerance of the flatness and parallelism that the customer has specified in the technical drawing which was $1 \%$ in this work. The bare steel was outside the tolerance limits (the flatness was 1.4945, and the parallelism was 1.7288) after production of 700 parts. Alloy B hardfacing did not reach the tolerance 
limit even after 1200 forging cycles. Another important result was the remanufacturing score. The British Standards Institute (BSI) defines remanufacturing as a process to: "Return a used product to at least its original performance with a warranty that is equivalent to or better than that of the newly manufactured product" [33]. Therefore, remanufacturing would offer the quickest route back to production [34]. Because hardfaced dies are subjected to less plastic deformation during hot forging performance than bare dies, they need less re-machined depth. The re-machined depth was about $9 \mathrm{~mm}$ for bare steel; it was 5 and $3 \mathrm{~mm}$ for Alloys B and D, respectively. As a result, the bare steel had been remanufactured 14 times over its lifetime. While the hardness of bare steel was $430 \mathrm{HV}$, the hardness of Alloy B was $469 \mathrm{HV}$, and the hardness of Alloy D was $499 \mathrm{HV}$. As is seen, hardfacing can lead to a significantly higher hardness and wear resistance in hot forging dies, since it can increase their lifetime by about 2- to 3-fold. Alloy B was remanufactured 25, and Alloy D 42 times. Hot forging trials were applied through a procedure that included heating the billet at $1200^{\circ} \mathrm{C}$, then forging it on a hammer machine. Since the initial temperature of the die is $300^{\circ} \mathrm{C}$, it is assumed that the temperature that is reached at its maximum is $400^{\circ} \mathrm{C}$ on the die surface [34]. When comparing the results from the hardfaced and bare die tests, an increase in temperature caused hardness to occur due to the formation of a hard and resistant layer on the surface of the hardfaced die which resulted in substantial improvements when it came to its wear resistance and lifetime.

\section{Conclusions}

In this work, the influence of hardfacing on the forging die's lifetime was studied. Through numerical simulations, experimental studies and hot forging performance tests it was found that hardfacing helps to reduce damage to the dies and extends their life.

All numerical analyses under defined conditions are credible and useful in the manufacturing industry. In many cases, trial-and-error procedures are neither optimal nor cost-effective in terms of achieving the desired properties of the final product. Data collection from the traditional experiments and also a measurement of high-temperature properties are expensive. Furthermore, these properties can be sensitive to microstructure and alloy composition. Estimation of physical, metallurgical and mechanical properties of hardfaced surfaces and behavior versus pressure during forging via numerical analysis can be beneficial when it comes to developing the appropriate forging procedure or material selection aspects of the hot forging process in respect to the failure resistance of a forging die.
Failure mechanisms in a hot forging dies that were used for actual production were investigated. It was found that the main factors that led to the failure of the dies were plastic deformation and cracking.

During the present work, a series of experiments were performed on 1.2714 hot-working tool steel that was hardfaced and bare. It was concluded that the room temperature wear tests were alone not reliable indicators for hot forging conditions due to the absence of cyclic thermal or mechanical shocks in pinon-disc wear experiments. The other properties such as hardness, oxide formation and mechanical, physical and metallurgical properties at elevated temperatures should all be considered together.

Hot forging is a severe process for any tool material. In the case of hardfacing with Alloys B and D, a hard surface layer was formed on the surface of a 1.2714 hot-working tool steel, as a result of a high amount of carbide precipitation that occurs inside the grains. This hard surface layer had good support that was provided by a tough sub-layer, and it created a protective coating against wear on the die surface. Which was done under real production conditions, this led to the bare steel being remanufactured 14 times, while Alloys B and D were remanufactured 25 and 42 times, respectively. Finally, Alloy D is the best hardfacing alloy in this study.

\section{Acknowledgements}

The authors would like to thank Celal Bayar University (Project Code: 2015-110) for providing financial support. The authors are thankful to EGEMET FORGE Inc. for providing samples and hot forging trials.

\section{References}

[1] Chander, S., Chawla, V.: Discovery, 52, 2016, p. 1231.

[2] Hawryluk, M.: Archives of Civil and Mechanical Engineering, 16, 2016, p. 845. doi:10.1016/j.acme.2016.06.001

[3] Podgornik, B., Leskovsek, V.: Materiali in Tehnologije/ Materials and Technology, 49, 2015, p. 313. doi:10.17222/mit.2015.005

[4] Kashani, H., Amadeh, A., Ghasemi, H. M.: Wear, 262, 2007, p. 800. doi:10.1016/j.wear.2006.08.028

[5] Lavtar, L., Muhic, T., Kugler, G., Terčelj, M.: Engineering Failure Analysis, 18, 2011, p. 1143. doi:10.1016/j.engfailanal.2010.11.002

[6] Summerville, E., Venkatesan, K., Subramanian, C.: Materials \& Design, 16, 1995, p. 289. doi:10.1016/0261-3069(96)00010-6

[7] Turk, R., Peruš, I., Terčelj, M.: International Journal of Machine Tools \& Manufacture, 44, 2004, p. 1319. doi:10.1016/j.ijmachtools.2004.04.020

[8] Amin, M., Ali, L.: Pak. Journal of Engineering and Applied Sciences, 12, 2013, p. 95. 
[9] Tušek, J., Taljat, B., Klobčar, D.: Metalurgija, 46, 2007, p. 67.

[10] Lazic, V., Sedmak A., Nikolic, R. R., Mutavdzic, M., Aleksandrovic, S., Krstic, B., Milosavljevic, D.: Materiali in Tehnologije/Materials and Technology, 49, 2015 , p. 165 .

[11] Gualco, A., Svoboda, H. S., Surian, E. S.: Wear, 360 361, 2016, p. 14. doi:10.1016/j.wear.2016.04.011

[12] Wang, Y., Gou, J., Chu, R., Zhen, D., Liu, S.: Tribology International, 103, 2016, p. 102. doi:10.1016/i.triboint.2016.06.041

[13] Singla,Y. K., Arora, N., Dwivedi, D. K.: Tribology International, 105, 2017, p. 229. doi:10.1016/i.triboint.2016.10.015

[14] Sun, S. D., Fabijanic, D., Ghaderi, A., Leary, M., Toton, J., Sun, S., Brandt, M., Easton, M.: Surface \& Coatings Technology, 296, 2016, p. 76. doi:10.1016/i.surfcoat.2016.03.061

[15] Yang, J., Wang, C., Xing, X., Yang, Y., Ren, X., Yang, Q.: Materials Science \& Engineering A, 670, 2016, p. 49. doi:10.1016/i.msea.2016.05.103

[16] Diekmann, U.: In: Proceedings of COMAT 2012. Ostrava, TANGER Ltd 2012.

[17] Ramasubbu, V., Chakraborty, G., Albert, S. K., Bhaduri, A. K.: Journal Materials Science and Technology, 27, 2011, p. 59. doi:10.1179/026708309X12526555493431

[18] Francis, J. A., Bednarz, B., Bee, J. V.: Science and Technology of Welding and Joining, 7, 2002, p. 95. doi:10.1179/136217102225001340

[19] Womersley, D.: Surface Engineering, 7, 1991, p. 61.

[20] Vander Voort, G. F., Manilova, E. P.: Advanced Materials and Processes, 163, 2005, p. 32.

[21] Durand-Charre, M.: Microstructure of Steels and Cast Irons. Berlin, Springer Science \& Business Media 2004.

[22] Liyanage, T., Fisher, G., Gerlich, A. P.: Surface and Coatings Technology, 205, 2010, p. 759. doi:10.1016/j.surfcoat.2010.07.095

[23] Shi, S., Lippold, J. C., Ramirez, J.: In: Proceedings of the 7th International Conference on Trends in Welding Research. Ed.: David, S. A. Materials Park, ASM International 2005, p. 293.
[24] Imurai, S., Thanachayanont, C. H., Pearce, J. T. H., Chairuangsri, T.: Archives of Metallurgy and Materials, 60, 2015, p. 919. doi:0.1515/amm-2015-0230

[25] Bedolla-Jacuinde, A., Correa, R., Mejía, I., Quezada, J. G., Rainforth, W. M.: Wear, 263, 2007, p. 808. doi:10.1016/j.wear.2006.12.011

[26] Fouilland, L., El Mansori, M., Massaq, A.: Journal of Materials Processing Technology, 209, 2009, p. 3366. doi:10.1016/j.jmatprotec.2008.07.039

[27] Hardell, J., Hernandez, S., Mozgovoy, S., Pelcastre, L., Courbon, C., Prakash, B.: Wear, 330-331, 2015, p. 223. doi:10.1016/j.wear.2015.02.040

[28] Zhang, Q. Y., Wang, S. Q., Zhou, Y., Chen, K. M., Wang, L., Cui, X. H.: Tribology International, 105, 2017, p. 334. doi:10.1016/j.triboint.2016.10.022

[29] Yukawa, N., Ishiguro, T., Abe, E., Ishikawa, T., Choda, T.: Procedia Engineering, 81, 2014, p. 492. doi:10.1016/i.proeng.2014.10.028

[30] Glasser, W. A.: Characterization of Tribological Materials. New York, Momentum Press, LLC 2010. ISBN13: 978-1-60650-181-8.

[31] Dejun, K., Haoyuan, G., Wenchang, W.: Tribology Transactions, 59, 2016, p. 604. http://www.tandfonline.com/doi/ref/10.1080/ 10402004.2015.1094842?.scroll=top

[32] Lavtar, L., Tercelj, M., Fazarinc, M., Kugler, G.: RMZ - Materials and Geoenvironment, 57, 2010, p. 453.

[33] British Standards Institution: Design for Manufacture, Assembly, Disassembly and End-of-Life Processing (MADE) Part 2: Terms and definitions. London, British Standards Institute 2009.

[34] Payne, G., Ahmad, A. S., Fitzpatrick, S., Xirouchakis, P., Ion, W., Wilson, M.: In: Proceedings of 14th International Conference on Manufacturing Research. Eds.: Goh, Y. M., Case, K. Amsterdam, IOPS Press 2016, p. 93. doi:10.3233/978-1-61499-668-2-93 